\title{
Diabetes Distress and Associated Factors in Patients with Diabetes Mellitus in South East Nigeria
}

\author{
Belonwu M. Onyenekwe Ekenechukwu E. Young Chidimma B. Nwatu \\ Christian I. Okafor Chidiebere V. Ugwueze \\ Department of Medicine, University of Nigeria Teaching Hospital, Enugu, Nigeria
}

\section{Keywords}

Prevalence - Diabetes distress · Screening - Severity ·

Associated factors $\cdot$ Management

\begin{abstract}
Background: Diabetes distress (DD) is a common worldwide problem in diabetic patients irrespective of age and type of treatment. In the DAWN 2 study (Diabetes Attitudes, Wishes, and Needs), DD was reported by $44.6 \%$ of participants. $\mathbf{O b}$ jectives: The purpose of this study was to assess the prevalence and level of DD and its associated factors among adult diabetic patients in South East Nigeria. Methods: The present study was cross-sectional and descriptive. Patients attending the adult diabetes clinic were enrolled. The questionnaire was administered by the investigators. All patients were eligible. Their demographic and clinical data were obtained. They were screened for DD using the DD Scale (DDS)2 and DDS-17. Data were tabulated and analyzed using SPSS version 21. Results: There were 110 subjects ( 38 males and 72 females), aged $36-85$ years $(60.5 \pm 10.0)$. Only $9(8.2 \%)$ had diabetes mellitus (DM) type 1, while the rest had type $2 \mathrm{DM}$. Twenty-five subjects (22.7\%) were on insulin injection. Hypertension was coexistent in $72 \%$, and they were prescribed
\end{abstract}

karger@karger.com www.karger.com/dde

Karger ${ }^{\prime \prime} \div$

GOPEN ACCESS
(C) 2020 The Author(s)

Published by S. Karger AG, Basel

This article is licensed under the Creative Commons AttributionNonCommercial-NoDerivatives 4.0 International License (CC BYNC-ND) (http://www.karger.com/Services/OpenAccessLicense) Usage and distribution for commercial purposes as well as any distribution of modified material requires written permission.
3-10 medications $(5.9 \pm 1.5)$ at the time of assessment. The male and female subjects were comparable. Moderate to severe DD was present in $51.9 \%$ (DDS-17). The average scores were for DDS-2, 3.1; DDS-17, 2.3; emotional burden, 2.9; physician-related distress, 1.4; regimen-related distress, 2.5 , and interpersonal distress, 2.2. Distress was significantly associated with a younger age, T1DM, longer duration of diabetes, use of insulin injection, and $\mathrm{HbA}_{1 \mathrm{C}}$ level. Conclusion: $\mathrm{DD}$ is a common consequence of living with diabetes and impairs diabetes self-care behavior and glycemic control. Active screening for DD should be an integral part of diabetes care. Diabetes self-management education and support should be implemented at diagnosis and as needed thereafter, especially when DD is diagnosed. $\quad 02020$ The Author(s)

Published by S. Karger AG, Basel

\section{Introduction}

People with diabetes are at increased risk for depression, anxiety, eating disorders, cognitive dysfunction/ dementia, diabetes distress (DD), psychological insulin resistance (reluctance or refusal to initiate insulin therapy), and persistent fear of hypoglycemia [1-5]. The 
presence of psychiatric comorbidities and DD is associated with reduced diabetes self-care and quality of life [1-6].

\section{Definition}

DD or diabetes-related distress is a form of emotional distress, which is specific to diabetes and reflects the emotional response to a demanding illness. It encompasses the significantly negative emotional reactions to all aspects of diabetes and diabetes care. This includes: DM diagnosis, threat of complications, self-management demands (testing and monitoring blood glucose level, compliance with dietary regimen, and engaging in regular physical activity), treatment, or unsupportive social structures surrounding diabetes $[7,8] . \mathrm{DD}$ is a rational response to the demands of a challenging long-term illness and is not considered a psychopathology. It differs from major depressive disorder in being content rather than symptom specific. While DD symptoms are similar to those of depression, they are not severe enough to meet the diagnostic criteria for major depressive disorder [7-9].

\section{Prevalence}

DD is a common worldwide problem in people with diabetes mellitus of all ages and has been demonstrated across various populations and cultures. It affects type 1 (T1DM) or type $2 \mathrm{DM}$ patients (T2DM) whether on insulin injection or not. In the DAWN 1 study (Diabetes Attitudes, Wishes, and Needs) [10], DD was reported by $41 \%$ of the participants and in DAWN 2 by $44.6 \%$ (17.2-67.6) [11]. In the same study, supporting a relative with diabetes was perceived as a burden by $35.3 \%(10.6-61.7 \%)[11,12]$.

\section{Screening for DD}

$\mathrm{DD}$ can be assessed using one of several patient-reported outcome measures. Two scales are accepted as statistically sound measures of DD [13]: the Problem Areas in Diabetes (PAID) scale $[14,15]$ and the DD Scale (DDS) $[16,17]$. Despite its strengths, the PAID scale had some drawbacks, including the absence of subscales to distinguish the various elements of DD and lack of questions addressing patients' experience with their health care providers. This prompted the development of a 17 -item questionnaire to measure DD (DDS-17). The DDS-17 distinguishes 4 main subscales from the principal term, which include: emotional burden (EB, 5 items), physician-related distress ( $\mathrm{PRD}, 4$ items), regimen-related distress ( $\mathrm{RRD}$, 5 items), and interpersonal distress (ID, 3 items), which represent different areas of potential diabetes-specific distress. DDS-17 uses a Likert scale with each item scored from 1 to 6 reflecting the distress experienced over the last month: 1 (not a problem), 2 (a slight problem), 3 (a moderate problem), 4 (a somewhat serious problem), 5 (a serious problem), and 6 (a very serious problem). Total possible scores for DDS-17 will be 17-102 (average 1-6). Thus, the actual average scores for the DDS-17 and their subscales yield 3 patient subgroups: little or no distress, $<2.0$; moderate distress, 2.0-2.9; high distress, $\geq 3.0$. A brief version; the DDS-2, which is a 2 -item instrument, was also developed for the initial screening of DD [18]. The same grading is used for scoring the DDS- 2 .

\section{Materials and Methods}

Study Objectives

The purpose of this study was to assess the prevalence and level of DD and its associated factors among adult diabetic patients attending a teaching hospital in South East Nigeria. The findings of this study will help to develop appropriate policy for prevention, control, and rehabilitation of patients with DD. The study also sought to establish how DDS-2 correlated with DDS-17 in the local population.

\section{Study Design}

The study was cross-sectional and descriptive and was conducted at the University of Nigeria Teaching Hospital Enugu, a premier teaching hospital in the South East of Nigeria. All patients were eligible for recruitment. However, those too ill, confused, or feeble were excluded. Consecutive patients with DM attending the outpatient adult diabetes clinic were recruited into the study. Their personal, anthropometric, and laboratory data were recorded.

\section{Screening for DD}

The DD level was assessed using DDS-17 and DDS-2. The questionnaire was administered by the investigators. The results were tabulated, and the DD level calculated for each subject and classified as previously described.

\section{Statistical Analysis}

Data were analyzed using SPSS version 21 (SPSS, Inc., Chicago, IL, USA). Descriptive statistics was used to describe the population, and $\chi^{2}$ test and Pearson correlation coefficient were used to analyze data for significant associations between variables. A $p$ value $<0.05$ was considered statistically significant. The Mann-Whitney $\mathrm{U}$ test was used to compare the male and female scores. Pointbiserial correlation was used to test the correlation between the distress scores and binary categorical variables.

\section{Results}

A total of 110 subjects were screened ( 38 males and 72 females). Their demographic and clinical data are presented in Table 1. All the participants were of Igbo ethic origin. Only $9(8.2 \%)$ were T1DM, while the rest were T2DM. For 
Table 1. Basic demographic and clinical data

\begin{tabular}{|c|c|}
\hline Total patients & $110(100 \%)$ \\
\hline Males & $38(34.5 \%)$ \\
\hline Females & $72(65.5 \%)$ \\
\hline \multicolumn{2}{|l|}{ Diabetes mellitus } \\
\hline T1DM & $9(8.2 \%)$ \\
\hline T2DM & $101(91.8 \%)$ \\
\hline Age, years & $36-85,60.5 \pm 10.0$ \\
\hline T1DM & $35-74,56.11 \pm 11.27$ \\
\hline T2DM & $41-85,60.90 \pm 0.9 .83$ \\
\hline \multicolumn{2}{|l|}{ Education } \\
\hline None & $8(7.2 \%)$ \\
\hline Primary & $38(34.5 \%)$ \\
\hline Secondary & $21(19.0 \%)$ \\
\hline Tertiary & $43(39.1 \%)$ \\
\hline \multicolumn{2}{|l|}{ Marital status } \\
\hline Married & $82(74.5 \%)$ \\
\hline Widowed & $25(22.7 \%)$ \\
\hline Single & $3(2.7 \%)$ \\
\hline \multicolumn{2}{|l|}{ Occupation } \\
\hline Professionals ${ }^{1}$ & $19(17 \%)$ \\
\hline Clerical, service ${ }^{2}$ & $16(14.5 \%)$ \\
\hline Craft, trade, elementary & $46(41.8 \%)$ \\
\hline Retired & $29(26.3 \%)$ \\
\hline \multicolumn{2}{|l|}{ DM treatment } \\
\hline Oral & $85(77.3 \%)$ \\
\hline Insulin & $25(22.7 \%)$ \\
\hline Hypertension & $79(71.8 \%)$ \\
\hline BMI, kg/m² & $18.1-43.3,27.4 \pm 5.1$ \\
\hline Waist circumference, $\mathrm{cm}$ & $61.0-129.0,93.2 \pm 12.3$ \\
\hline Waist/hip ratio & $0.77-2.0,0.94 .5 \pm 0.13$ \\
\hline Medications, $n$ & $3-10,5.9 \pm 1.5$ \\
\hline $\mathrm{HbA}_{1 \mathrm{C}}, \%$ & $5.2-16.4,8.9 \pm 2.4$ \\
\hline
\end{tabular}

Numbers (\%), ranges (min-max), and means \pm SD are shown. ${ }^{1}$ Managers, professionals, associated professionals, technicians. ${ }^{2}$ Clerical, sales, and service workers.

the purpose of analyses, subjects were classified as having T1DM if they were diagnosed with diabetes before the age of 40 years and were treated with insulin both at diagnosis and at the time of the survey. The subjects were aged 35-85 years with a mean \pm SD of $60.5 \pm 10.0$ years. The mean age for subjects with T1DM was $56.1 \pm 11.3$ years and for those with T2DM $60.9 \pm 9.8$ years. The duration of DM ranged from 1 to 42 years, with a mean of $10.8 \pm 8.6$ years (T1DM $22.4 \pm 9.9$ years and T2DM $9.9 \pm 7.6$ years). On the whole, $25(22.7 \%)$ subjects were on insulin injection (basal and mixed insulin) in addition to oral glucose-lowering medications and appropriate diet therapy while the rest were on oral medications. Hypertension was coexistent in $72 \%$ of the subjects. The subjects were prescribed 3-10 medications $(5.9 \pm 1.5)$ at the time of assessment. The male and female subjects were comparable in their demographics
Table 2. Diabetes distress scale (DDS) scores

\begin{tabular}{lllll}
\hline DDS & $\begin{array}{l}\text { Males } \\
(n=38)\end{array}$ & $\begin{array}{l}\text { Females } \\
(n=72)\end{array}$ & $\begin{array}{l}\text { Total } \\
(n=110)\end{array}$ & $p$ value \\
\hline DDS-2 & $2.6 \pm 1.4$ & $3.2 \pm 1.7$ & $3.1 \pm 1.6$ & 0.056 \\
DDS-17 & $2.1 \pm 1.0$ & $2.5 \pm 1.2$ & $2.3 \pm 1.2$ & 0.094 \\
EB & $2.7 \pm 1.4$ & $3.0 \pm 1.8$ & $2.9 \pm 1.6$ & 0.398 \\
PRD & $1.2 \pm 0.31$ & $1.6 \pm 0.78$ & $1.4 \pm .68$ & 0.001 \\
RRD & $2.2 \pm 1.1$ & $2.7 \pm 1.4$ & $2.5 \pm 1.3$ & 0.099 \\
ID & $1.8 \pm 1.2$ & $2.4 \pm 1.6$ & $2.2 \pm 1.5$ & 0.024 \\
\hline & T1DM & & T2DM & \\
\hline DM type & & & & \\
DDS-2 & $4.4 \pm 1.7$ & & $2.9 \pm 1.6$ & 0.018 \\
DDS-17 & $3.4 \pm 1.3$ & & $2.2 \pm 1.1$ & 0.014 \\
\hline
\end{tabular}

Means \pm SD. DM, diabetes mellitus; EB, emotional burden; $\mathrm{PRD}$, physician-related distress; RRD, regimen-related distress; ID, interpersonal distress. Statistically significant values are italicized.

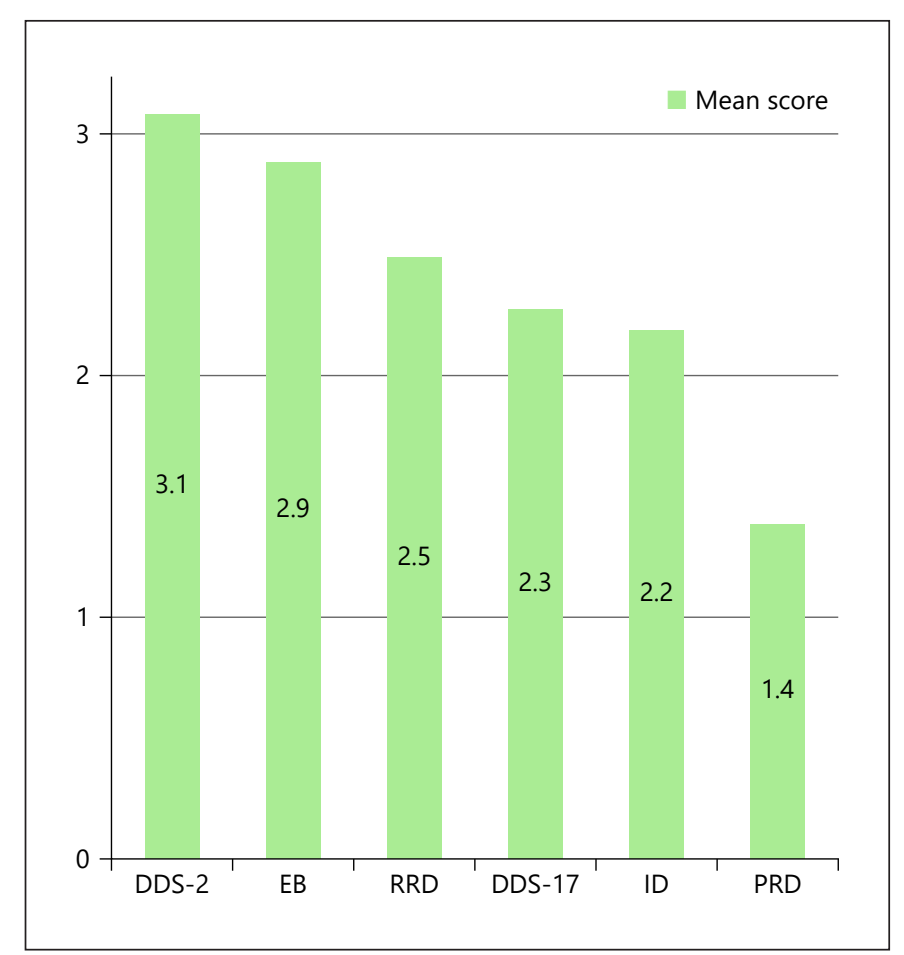

Fig. 1. Mean diabetes distress scores.

and differed significantly only in their occupation, BMI, waist circumference and waist/hip ratio $(p=0.030, p=$ $0.013, p<0.001$, and $p<0.001$ respectively). The overall average scores were: DDS-2, $3.1 \pm 1.6$ and DDS-17, $2.3 \pm$ 


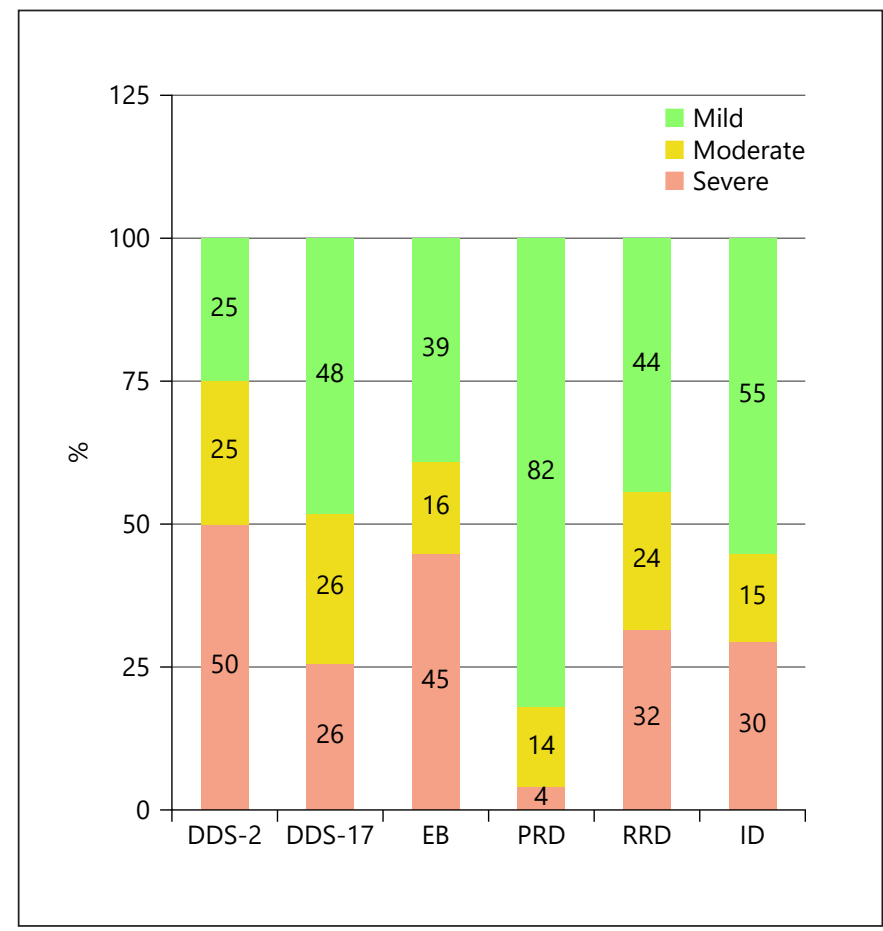

Fig. 2. Grading of diabetes distress scores.

1.2 (Table 2). Average scores for T1DM were DDS-2, $4.4 \pm$ 1.7 and DDS-17, $3.4 \pm 1.3$ and for T2DM, DDS-2, $2.9 \pm 1.6$ and DDS-17, $2.2 \pm 1.1$ (Table 2). The difference was statistically significant ( $p=-0.018$ and $p=0.014$, respectively). The average scores for the subscales were summarized in Table 2 and Figure 1. Moderate DD was recorded in all categories except for PRD. In ID, males recorded mild and females had moderate distress. Among the subscales, EB received the highest scores followed by RRD. PRD was the least. Males and females differed significantly in their scores for DDS-PRD ( $p=0.001)$ and -ID $(p=0.024)$. Scores for the different parameters of distress were graded in terms of severity (Table 3; Fig. 2). DD (score $\geq 2$ or moderate to severe distress) was present in $75.5 \%$ for DDS-2, $51.9 \%$ for DDS-17, 60.5\% for EB, $17.2 \%$ for PRD, $55.4 \%$ for RRD, and $45.5 \%$ for ID. Pearson correlation was used to check the relationships between different DD scores. DDS-2 correlated strongly with DDS-17 $(r=0.835, p<0.001)$, and most strongly with $\mathrm{EB}(r=0.859, p<001)$ as well as the other subscales: PRD $(r=0.435, p<0.001)$; RRD $(r=0.770, p<$ $0.001)$, and ID ( $r=0.607, p<0.001$; Cronbach's $\alpha 0.92)$. Further bivariate analysis was carried out to determine associations between the clinical and metabolic factors that contributed to, or were associated with, DD (age, and type, duration, and treatment of DM, presence of hypertension,
Table 3. Diabetes distress (DD) severity

\begin{tabular}{llll}
\hline \multirow{4}{*}{ DD severity, $n(\%)$} \\
\cline { 2 - 4 } & mild & moderate & severe \\
\hline DDS-2 & $27(24.5)$ & $27(24.5)$ & $58(50.9)$ \\
DDS-17 & $53(48.2)$ & $28(25.5)$ & $29(26.4)$ \\
EB & $43(39.1)$ & $15(13.6)$ & $50(45.5)$ \\
PRD & $91(82.7)$ & $15(13.6)$ & $4(3.6)$ \\
RRD & $49(44.5)$ & $26(23.6)$ & $35(31.8)$ \\
ID & $60(54.5)$ & $17(15.5)$ & $33(30.0)$ \\
\hline
\end{tabular}

See legend to Table 2 for more information.

number of medications, $\mathrm{HbA}_{1 \mathrm{C}}$, and presence of diabetic peripheral neuropathy). The results are presented in Table 4. It became evident that the effect of different clinical and health variables was not uniform. Age correlated negatively with DD in all scales and subscales except for PRD. DM type (T1DM) recorded significant distress across all the DD scales and subscales. EB had significant association with DM type and higher $\mathrm{HbA}_{1 \mathrm{C}}$ levels; $\mathrm{PRD}$ and RRD with DM type; and treatment (use of insulin) and ID with DM type (T1DM), DM treatment, and $\mathrm{HbA}_{1 \mathrm{C}}$ level. Elevated $\mathrm{HbA}_{1 \mathrm{C}}$ level was a significant association only in $\mathrm{EB}$ and ID.

\section{Discussion}

The prevalence of overall DD obtained by DDS-17 (52\%) in this study was comparable to figures obtained by the DAWN 2 study (17.2-67.6\%) [12]. Various figures have been reported from studies in different regions of the world: Sudan, 87.6\% [19]; Trinidad, 56.1\% [20]; Malaysia, 49.2\% [21]; Bangladesh, 48.5\% [22]; South Africa, 44\% [23]; Canada, 39\% [24]; Brazil, 31.5\% [25]; and Saudi Arabia, 25\% [26]. Fisher at al. [27] reported a DD prevalence of $42.1 \%$ in adults with T1DM. In this study, subjects with T1DM had significantly higher distress scores in all scales compared to those with T2DM. This is probably related to their younger age, use of insulin for treatment, and longer duration of diabetes. Patients with T1DM were younger at the time of diagnosis and may have fewer coping mechanisms than those with T2DM. Cost of medications, a more difficult therapeutic regimen, and the various social, psychological, and physical stressors faced by younger people were thus contributory [28]. The high DDS scores underscore the need for intensive support and education for them, which sadly is not always available in resource-constrained settings such as ours. The STePS (Supporting
Onyenekwe/Young/Nwatu/Okafor/ Ugwueze 
Table 4. Relationship between mean diabetes distress scores (DDS) and health variables

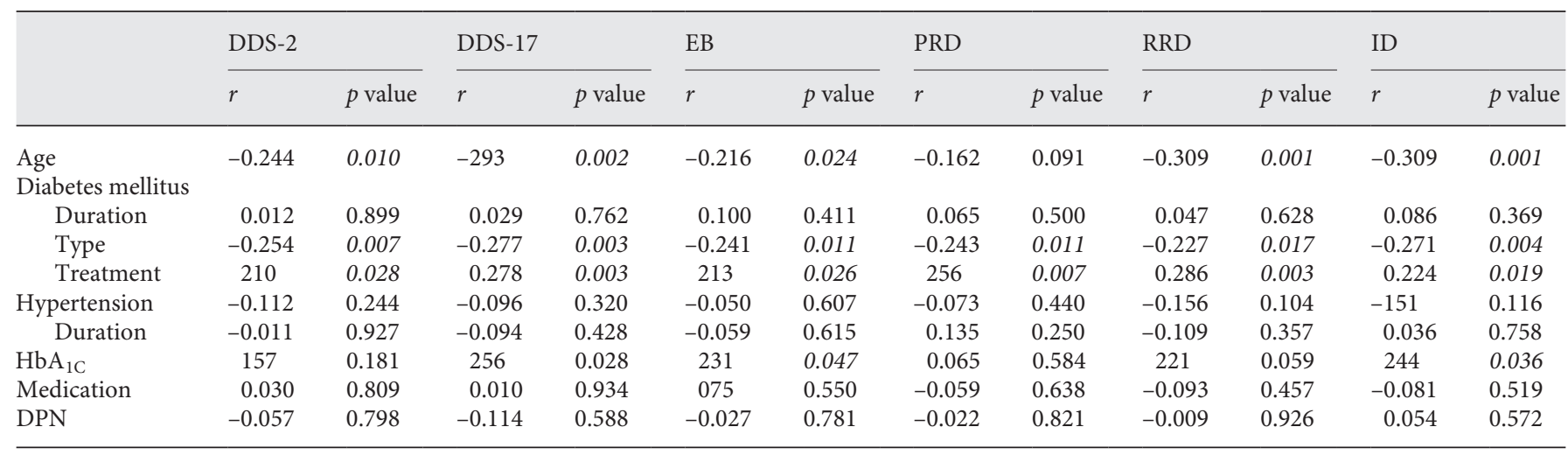

DPN, diabetic peripheral neuropathy. See legend to Table 2 for more information.

Teens Problems Solving) study was an intensive resilience intervention program to prevent the development of DD in adolescents with T1DM, of which early results are promising [29]. In the T1-REDEEM, a randomized controlled trial to reduce DD among adults with T1DM, DD was successfully reduced using both education/behavioral and emotion-focused approaches [30]. In the same vein, Ramaj et al. [31] reported better control of diabetes and a significantly improved level of emotional distress by additional education of diabetic patients with DD. Insulin distress is a major contributor to DD [32]. T1DM and T2DM subjects on insulin injections recorded high DD (Table 4). Insulin distress is defined as an emotional response to a suggestion to use insulin, characterized by extreme apprehension, discomfort, dejection, or denial due to a perceived inability to cope with the requirements of insulin therapy [32]. In our practice, patients view suggestion of insulin use as a sign of an ominous deterioration in their condition, and it evokes considerable apprehension. EB was the dominant form of distress in most studies, as was also recorded in this report. In this study, only $\mathrm{EB}$ and ID were linked to higher $\mathrm{HbA}_{1 \mathrm{C}}$ levels. This is not surprising. Constant coping with diabetes management and fears of complications and reduced life expectancy can produce wear and tear on a patient's psyche, and thus impair quality of life and self-care. Analysis of the scores of the subscales underscores the point that while average scores may be within normal limits, the subscales may reveal areas of significant distress warranting attention (Table 4). Scores for PRD were the lowest. The subjects were generally satisfied with their caregivers. PRD was almost always related to their being unable to see the physician of their choice. This was seen more in females, who had sig- nificantly higher PRD scores than males $(p=0.012)$ and in T1DM. Psychological attachment to a specific physician may be more common in females than males, though this observation will need to be further verified. For T1DM, it may be related to the physicians they have bonded with over the many years they have been attending a hospital. In a report by Slean et al. [33], better doctor communication behavior and higher trust in physicians was associated with lower EB among patients with diabetes. The DDS- 2 correlated strongly with both DDS-17 and the subscales. The correlation was strongest with EB. This is quite significant, as the average EB score was the highest of all the subscales for the study subjects. This is indicative of the DDS-2 as a good tool for the initial assessment of $\mathrm{DD}$ as it correlated very strongly with $\mathrm{EB}$, the dominant source of DD. The usual demographic and health factors associated with DD were reproduced in this study. It has been noted that diabetes self-management in Sub-Saharan Africa is generally poor and a serious threat to glycemic control. Self-monitoring of blood glucose, physical activity, and risk reduction behavior are insufficient $[34,35]$. A report by Ogbera and Adeyemi-Doro [35] in Nigeria concluded that psychosocial factors directly influence glycemic control and diabetes self-care habits. Current guidelines on diabetes management incorporate screening for DD [36]. Screening should be done at diabetes diagnosis, during regularly scheduled management visits, during hospitalizations, with new onset of complications, or when problems with glucose control, quality of life, or self-management are identified [37]. The DDS-2 is useful for the initial DD screening. Distressed persons can then proceed to the full DDS-17 assessment. Moderate to high DD scores, as well as individual items in the subscales 
identified as problem areas, present the focus for a therapeutic conversation, which simply means listening to and showing an understanding and awareness of the psychosocial and emotional issues associated with diabetes [13]. Individuals with DD should receive diabetes self-management education and support (DSME/S) [37] and should be followed up to determine improvement in their scores. The incorporation of DD screening and management into national diabetes care guidelines is significant.

Emotional well-being is an important part of diabetes care and self-management. DD is a common consequence of living with diabetes and impairs diabetes self-care behavior and glycemic control. Health practitioners should be well aware of this. Active screening for DD should be an integral part of diabetes care. DSME/S is fundamental for implementing and sustaining coping skills and behaviors needed to self-manage diabetes on an ongoing basis. The recommendation of the guidelines that individuals with diabetes receive DSME/S especially at diagnosis and as needed thereafter is a good starting point.

\section{Statement of Ethics}

The study protocol was approved by the UNTH Research Ethics Committee. The subjects gave informed consent.

\section{Conflict of Interest Statement}

The authors have no conflicts of interest to declare.

\section{Funding Sources}

The authors received no funding for the study.

\section{Author Contributions}

All the authors were involved in the concept and design of the study, acquisition, analysis, and interpretation of data, drafting and revision of the article, and in the final approval of the version to be published.

\section{References}

1 Kruse J, Schmitz N, Thefeld W; German National Health Interview and Examination Survey. On the association between diabetes and mental disorders in a community sample: results from the German National Health Interview and Examination Survey. Diabetes Care. 2003 Jun;26(6):1841-6.

2 Das-Munshi J, Stewart R, Ismail K, Bebbington PE, Jenkins R, Prince MJ. Diabetes, common mental disorders, and disability: findings from the UK National Psychiatric Morbidity Survey. Psychosom Med. 2007 Jul-Aug; 69(6):543-50.

3 Lin EH, Von Korff M, Alonso J, Angermeyer MC, Anthony J, Bromet E, et al. Mental disorders among persons with diabetes-results from the World Mental Health Surveys. J Psychosom Res. 2008 Dec;65(6):571-80.

4 Polonsky WH, Fisher L, Guzman S, Villa-Caballero L, Edelman SV. Psychological insulin resistance in patients with type 2 diabetes: the scope of the problem. Diabetes Care. 2005 Oct;28(10):2543-5.

5 Robinson DJ, Coons M, Haensel H, Vallis M, Yale JF; Diabetes Canada Clinical Practice Guidelines Expert Committee. Diabetes and Mental Health. Can J Diabetes. 2018 Apr;42 Suppl 1:S130-41.

6 Fisher L, Mullan JT, Arean P, Glasgow RE, Hessler D, Masharani U. Diabetes distress but not clinical depression or depressive symptoms is associated with glycemic control in both cross-sectional and longitudinal analyses. Diabetes Care. 2010 Jan;33(1): 23-8.
7 Stanković Z, Jasović-Gasić M, Lecić-Tosevski D. Psychological problems in patients with type 2 diabetes-clinical considerations. Vojnosanit Pregl. 2013 Dec;70(12):1138-44.

8 Fisher L, Gonzalez JS, Polonsky WH. The confusing tale of depression and distress in patients with diabetes: a call for greater clarity and precision. Diabet Med. 2014 Jul;31(7): 764-72.

9 Fisher L, Skaff MM, Mullan JT, Arean P, Mohr D, Masharani U, et al. Clinical depression versus distress among patients with type 2 diabetes: not just a question of semantics. Diabetes Care. 2007 Mar;30(3):542-8.

10 Peyrot M, Rubin RR, Lauritzen T, Snoek FJ, Matthews DR, Skovlund SE. Psychosocial problems and barriers to improved diabetes management: results of the Cross-National Diabetes Attitudes, Wishes and Needs (DAWN) Study. Diabet Med. 2005 Oct; 22(10):1379-85.

11 Nicolucci A, Kovacs Burns K, Holt RI, Comaschi $\mathrm{M}$, Hermanns $\mathrm{N}$, Ishii $\mathrm{H}$, et al.; DAWN2 Study Group. Diabetes Attitudes, Wishes and Needs second study (DAWN2 ${ }^{\mathrm{TM}}$ ): cross-national benchmarking of diabetes-related psychosocial outcomes for people with diabetes. Diabet Med. 2013 Jul;30(7):767-77.

12 Kovacs Burns K, Nicolucci A, Holt RI, Willaing I, Hermanns N, Kalra S, et al.; DAWN2 Study Group. Diabetes Attitudes, Wishes and Needs second study (DAWN2 ${ }^{\mathrm{TM}}$ ): cross-national benchmarking indicators for family members living with people with diabetes. Diabet Med. 2013 Jul;30(7):778-88.
13 Berry E, Lockhart S, Davies M, Lindsay JR, Dempster M. Diabetes distress: understanding the hidden struggles of living with diabetes and exploring intervention strategies. Postgrad Med J. 2015 May;91(1075):278-83.

14 Polonsky WH, Anderson BJ, Lohrer PA, Welch G, Jacobson AM, Aponte JE, et al. Assessment of diabetes-related distress. Diabetes Care. 1995 Jun;18(6):754-60.

15 Welch GW, Jacobson AM, Polonsky WH The problem areas in diabetes scale. An evaluation of its clinical utility. Diabetes Care. 1997 May;20(5):760-6.

16 Polonsky WH, Fisher L, Earles J, Dudl RJ, Lees J, Mullan J, et al. Assessing psychosocial distress in diabetes: development of the diabetes distress scale. Diabetes Care. 2005 Mar;28(3):626-31.

17 Fisher L, Hessler DM, Polonsky WH, Mullan $\mathrm{J}$. When is diabetes distress clinically meaningful? Establishing cut points for the Diabetes Distress Scale. Diabetes Care. 2012 Feb; 35(2):259-64.

18 Fisher L, Glasgow RE, Mullan JT, Skaff MM, Polonsky WH. Development of a brief diabetes distress screening instrument. Ann Fam Med. 2008 May-Jun;6(3):246-52.

19 Mirghani HO. Distress and psychopathology among Sudanese patients with type 2 diabetes mellitus and its relation to glycaemic control. J Taibah Univ Med Sci. 2017 Apr;12(4):298-303.

20 Kameel M, Lilly P, Brandon R, Koreen P. The Dawn (Diabetes: Attitudes, Wishes and Needs) of type 2 diabetes mellitus in Trinidad, a small middle income developing country. Curr Res Diabetes Obes J. 2017;2(2):555583. 
21 Chew BH, Vos R, Mohd-Sidik S, Rutten GE. Diabetes-related distress, depression and distress-depression among adults with type $2 \mathrm{di}$ abetes mellitus in Malaysia. PLoS One. 2016; 11(3):e0152095.

22 Islam MR1, Karim MR, Habib SH, Yesmin K. Diabetes distress among type 2 diabetic patients. Int J Med Biomed Res. 2013;2(2):11324.

23 Ramkisson S, Joseph Pillay B, Sartorius B. Diabetes distress and related factors in South African adults with type 2 diabetes. J Endocrinol Metab Diabetes South Africa. 2016;21(2): 35-9.

24 Wong EM, Afshar R, Qian H, Zhang M, Elliott TG, Tang TS. Diabetes distress, depression and glycemic control in a Canadianbased specialty care setting. Can J Diabetes. 2017 Aug;41(4):362-5.

25 Zanchetta FC, Trevisan DD, Apolinario PP, Silva JB, Lima MH. Clinical and sociodemographic variables associated with diabetes-related distress in patients with type 2 diabetes mellitus. Einstein (Sao Paulo). 2016 Jul-Sep; 14(3):346-51.
26 Aljuaid MO, Almutairi AM, Assiri MA, Almalki DM, Alswat K. Diabetes-related distress assessment among type 2 diabetes patients. J Diabetes Res. 2018 Mar;2018:7328128.

27 Fisher L, Hessler D, Polonsky W, Strycker L, Masharani U, Peters A. Diabetes distress in adults with type 1 diabetes: prevalence, incidence and change over time. J Diabetes Complications. 2016 Aug;30(6):1123-8.

28 Hapunda G, Abubakar A, van de Vijver F, Pouwer F. Living with type 1 diabetes is challenging for Zambian adolescents: qualitative data on stress, coping with stress and quality of care and life [Internet]. BMC Endocr Disord. 2015 Apr;15(1):20. [cited 2019 Aug 12].

29 Hood KK, Iturralde E, Rausch J, WeissbergBenchell J. Preventing diabetes distress in adolescents with type 1 diabetes: results 1 year after participation in the STePS program. Diabetes Care. 2018 Aug;41(8):1623-30.

30 Fisher L, Hessler D, Polonsky WH, Masharani U, Guzman S, Bowyer V, et al. T1-REDEEM: a randomized controlled trial to reduce diabetes distress among adults with type 1 diabetes. Diabetes Care. 2018 Sep;41(9):1862-9.
31 Ramaj A, Kamberi F, Behrens J. Effects of diabetes education on emotional distress in patients with type 2 diabetes - an experimental study. Open J Endocr Metab Dis. 2019;09(02): 9-20.

32 Kalra S, Balhara YP. Insulin distress. US Endocrinol. 2018;14(1):27.

33 Slean GR, Jacobs EA, Lahiff M, Fisher L, Fernandez A. Aspects of culturally competent care are associated with less emotional burden among patients with diabetes. Med Care. 2012 Sep;50(9 Suppl 2):S69-73.

34 Stephani V, Opoku D, Beran D. Self-management of diabetes in Sub-Saharan Africa: a systematic review. BMC Public Health. 2018 Sep; 18(1): 1148

35 Ogbera A, Adeyemi-Doro A. Emotional distress is associated with poor self care in type 2 diabetes mellitus. J Diabetes. 2011 Dec;3(4): 348-52.

36 American Diabetes Association. Standards of medical care in diabetes. Diabetes Care. 2019; 42(Suppl 1).

37 Powers MA, Bardsley J, Cypress M, Duker P, Funnell MM, Fischl AH, et al. Diabetes selfmanagement education and support in type 2 diabetes. Diabetes Educ. 2017 Feb;43(1):4053. 